\title{
EAl Endorsed Transactions

\section{The Task of Walking Straight as an Interactive Serious Game for Blind Children}

\author{
Marcella Mandanici ${ }^{1, *}$, Antonio Rodà ${ }^{1}$, Marco Ricca $^{2}$ \\ ${ }^{1}$ University of Padova, Dept. of Information Engineering, via Gradenigo 6 - 35131 Padova (IT) \\ ${ }^{2}$ Fondazione Robert Hollman, Via Siena 1 - 35143 Padova (IT)
}

\section{Abstract}

This paper describes "Following the Cuckoo Sound", a responsive floor system designed to train blind children in walking straight. Its characteristics and potentialities are evaluated in the framework of the guidelines of instruction and assistance to blind children defined by two government agencies. Veering data analysis confirm the validity of the game in correcting both the initial orientation error and the errors in the step direction and provide further insights about veering and its relationship with walking speed and participants' clinical or experiential conditions. Moreover the system provides an engaging sensorial experience which fits not only the orientation and mobility programs but also other areas of the curriculum for blind children such as sensory efficiency, recreation and leisure, and education in the use of technology.

Received on 31 May 2018; accepted on 22 June 2018; published on 13 September 2018

Keywords: childhood blindness, veering, serious games, orientation and mobility training.

Copyright (c) 2018 Marcella Mandanici et al., licensed to EAI. This is an open access article distributed under the terms of the Creative Commons Attribution license (http://creativecommons.org/licenses/by/3.0/), which permits unlimited use, distribution and reproduction in any medium so long as the original work is properly cited.

doi:10.4108/eai.13-7-2018.155165

\section{Introduction}

It has been estimated that among the 253 millions of visually impaired people in the world, 1.4 million are children with irreversible blindness[1]. The causes of childhood blindness ${ }^{1}$ depend on the socioeconomic situation of the country of birth and are due primarily to corneal blindness (responsible of $70 \%$ of childhood blindness in poor countries), cataract, retinopathy of prematurity (ROP), refractive errors and low vision [2]. Whatever their pathology, these children have to face a whole life of problems due to visual impairment and for this reason they require special care and specific training curricula. To meet the needs of blind children various government agencies defined curriculum guides with the aim of building a framework for delivering appropriate instruction and assistance. Among these, authors selected the two most structured: Expanded Core Curriculum (ECC) [3] and the Guide to Curriculum for Visually Impaired Children

\footnotetext{
*Corresponding author. Email: mandanici@dei.unipd.it

${ }^{1}$ Childhood is defined as ranging from 0 to 15 years by UNICEF. Legal blindness is defined by get U.S. Social Security Administration (SSA) if the subject has less than 20/200 of visual acuity in the better eye or has less than 10 degrees in the central visual filed for each eye.
}

from the Education Bureau of the Government of the Hong Kong Special Administrative Region [4]. In the following, these documents are described and analyzed.

\subsection{The Expanded Core Curriculum}

The Expanded Core Curriculum (ECC) has been defined in the late 1980's as a part of the USA National Agenda [5]. The ECC is a set of skills and knowledge needed by students with visual impairments in addition to the core of the general academic curriculum. It consists of nine areas:

(i) compensatory or functional academic skills, including communication modes;

(ii) orientation and mobility;

(iii) social interaction skills;

(iv) independent living skills;

(v) recreation and leisure skills;

(vi) career education;

(vii) use of assistive technology;

(viii) sensory efficiency skills; 
(viii) self determination.

Particularly the orientation and mobility (O\&M) area is essential for blind children, as difficulty in locomotion is one of the primary effects of their impairment. O\&M is missing in the general curriculum and consequently this area requires the preparation of specifically trained teachers who can help blind students in achieving information about themselves and the environment where they move. Social interaction and recreation and leisure skills are also very important for the development of a balanced personality in blind children. As vision is the pre-condition of the majority of social relationships in sighted children, social interaction must be learned from the basics by blind children and must be achieved as the result of a thorough and conscious instructional activity. Training in the use of assistive technology may disclose a world rich of many possibilities and for this reason is an unmissable resource in the curriculum of a blind child. Sensory efficiency as the ability to exploit any possible residual vision, hearing, touch and smell, is the main channel through which information about the outer world can reach visually impaired children. To learn to sense the world and to interpret reality through any input different from vision is an ability fundamental to the expanded curriculum. On the whole the ECC envisions the future of a blind children as an active and autonomous member of the society. Moreover, the various areas of ECC may be expanded to offer to educators the means for addressing the needs of blind children who suffer of additional impairments such as cognitive and/or physical disabilities.

\subsection{The Guide to Curriculum for Visually Impaired Children}

Written by the Committee on Special Educational Needs, (CSEN 1996) under the Curriculum Development Council of the Hong Kong Government ${ }^{2}$, the Guide to Curriculum for Visually Impaired Children aims at formulating educational needs for visually impaired children. First a list of learning difficulties encountered by blind children is defined. These are “... difficulties in the perception and the formation of concepts, delay in physical and motor developments, problems in social interaction and difficulties in visual functions due to poor near vision, tunnel or patchy vision." 3 Different curriculum adjustments are proposed based on the total blindness or low vision condition. For the totally blind and severe low vision children, many integrations are proposed regarding subjects common to the general curriculum.

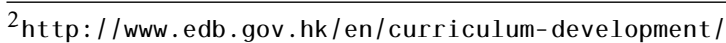
ma jor-level-of-edu/special-educational-needs/index.html ${ }^{3}$ https://cd.edb.gov.hk/la_03/chi/curr_guides/Visually/ index-EV.htm
}

Table 1. The O\&M training program of the CSEN (Hong Kong) subdivided in age groups

\begin{tabular}{|c|c|c|c|}
\hline & Environment & Aims & Skills \\
\hline $\begin{array}{l}\text { Junior } \\
\text { Primary Level }\end{array}$ & Controlled & $\begin{array}{l}\text { Development of sensory } \\
\text { awareness and utilization } \\
\text { (hear, touch, smell, } \\
\text { and kinesthetic sense) }\end{array}$ & \\
\hline $\begin{array}{l}\text { Senior } \\
\text { Primary Level }\end{array}$ & $\begin{array}{l}\text { Less controlled } \\
\text { (outdoor) }\end{array}$ & $\begin{array}{l}\text { Non-visual orientation } \\
\text { and navigation skills } \\
\text { also in different } \\
\text { weather conditions }\end{array}$ & $\begin{array}{l}\text { 1. implications of traffic } \\
\text { rules and regulations } \\
\text { 2. auditory analysis of } \\
\text { traffic patterns } \\
\text { 3. development of } \\
\text { advanced cane skills } \\
\text { 4. selection of } \\
\text { appropriate means of } \\
\text { transport } \\
\text { 5. use of good judgment } \\
\text { under changing } \\
\text { conditions } \\
\text { 6. transfer of acquired } \\
\text { skills to new situations } \\
\text { 7. appropriate } \\
\text { interactions with } \\
\text { the public }\end{array}$ \\
\hline $\begin{array}{l}\text { Secondary } \\
\text { Level }\end{array}$ & $\begin{array}{c}\text { Non controlled } \\
\text { (depending on maturity) }\end{array}$ & Independent traveling & \\
\hline
\end{tabular}

Among them there are the use of computers (training in keyboard skills or other computer access devices, learning of programming skills, exposure to a variety of computer applications and emphasis on the learning of word-processing) and music (listening activities, the use of Braille for music notation and singing). As in the ECC, there are communicative and social skills and O\&M training programs. This latter has special recommendations for junior primary level, senior primary level and secondary level students ${ }^{4}$.

Progress of the O\&M training program is shown in Table 1. The O\&M training program must be calibrated on the health conditions of the children and on their difficulties and sensory impairments that could affect equilibrium, co-ordination, flexibility and agility. The core of the program takes place at the Senior Primary Level in a semi-controlled environment, but it is clear that it is based on the sensory education achieved at the Junior Primary Level. The final goal (independent traveling) in not guaranteed and depends on the maturity, motivation and desire of integration of the subject.

\subsection{Veering in the Orientation and Mobility Training}

It has already been emphasized that the O\&M training is one of the fundamental parts of a blind person's curriculum. The lack of the ability to move autonomously and to explore the environment around oneself can be a reason of isolation and depression for the blind person and in the long term can be the cause of a severe cognitive deficit. One of the main problems in blind persons' navigation is veering,

\footnotetext{
${ }^{4}$ In the Hong Kong education system junior primary level includes children from 6 to 12 years old, junior secondary from 12 to 15 end secondary level from 15 to 18 . https://www.classbase.com/ countries/Hong-Kong/Education-System
} 
which is the inability to walk straight from a point to another. Veering emerged as a basic problem for blinds' navigation since 1955, when one of the first studies about veering was conducted by Rouse and Worchel [6], and was further studied by Cratty and Williams in a long series of experiments [7]. Guth and LaDuke [8] enumerate at least three main drawbacks of veering for blind people:

(i) veering may cause serious risks in many real life scenarios (walking in the traffic, crossing streets, walk on train platforms and so on);

(ii) veering implies to travel for longer distances to arrive to a determined target point;

(iii) veering falsifies the spatial relationships useful to build a cognitive map of the environment.

In spite of all the studies about veering, the causes of this behavior remain still unclear. Veering has been attributed to a natural tendency to walk in circles due to accumulating noise of the sensorimotor system [9], to deviations in single step orientation [10], to encoding errors in path integration [11] or to slight asymmetries in the two limbs [12]. One of the most important processes that underlie human locomotion is spatial updating, which provides fresh data about object distances and directions, delivering to the sensorimotor system important information to correct veering while moving. While sighted walkers can quickly update spatial information through vision, these data are available to blind walkers only through hearing, haptics, proprioception and kinestethic sense in a much slower and less precise way [13]. Moreover there are situations where hearing and haptics may be unavailable and where a blind person's navigation has to rely only on the so called dead reckoning technique, that is recalling from memory proprioceptive and kinesthetic cues about distances and turns [11]. This is the reason why training is very important to reduce veering [14] and why the sensory education present in the EEC (sensory efficiency skills) and in the Guide to Curriculum for Visually Impaired Children of CSEN is an essential part of a blind person's curriculum. Moreover, in the case of blind children, it is important to train sensory perception as early as possible to help them in the development of orientation and mobility skills [15].

\subsection{Serious Games for the O\&M Training of Blind Children}

Many sensory substitution devices have been proposed to help blind people's navigation by transforming images into sound (for example Sonic Eye [16]) or haptic output [17]. Nevertheless, these devices suffer of a very low user acceptance due to invasiveness, cognitive load, need of specific training, lack of multisensory integration and action perception link, lack of clinical validations [18]. This mismatch between blind people's needs and research trends is confirmed also by the shortage of literature reports about serious games for blind children. In spite of the fact that gamification has been recognized as a valid tool for rehabilitation [19], there is a relatively small number of examples of serious games developed for the O\&M training of blind children. Among these, authors found AudioDoom, an audio-based "first-person shooter" computer game [20]; a ping-pong game with interactive audio rendering [21]; and Movawii, a virtual environment game to help wayfinding and orientation [22]. A particularly interesting tool is the $A B B I$ bracelet, which outputs an audio signal as soon as the blind child moves. This audio feedback has also been employed in social games where blind children can not only enhance their O\&M abilities but also interact with other not-sighted pears [23]. This short review outlines the need of applications which engage blind children in O\&M exercises in a playful and relaxing way, without overloading them with invasive devices or too complex tasks. Children need to feel confident and possibly have fun during the training. For this reasons hand-free interaction and the use of gameful elements are good design elements for this task.

\subsection{Article Outline}

In the following Section authors introduce Following the Cuckoo Sound, a responsive floor application created to train blind children in walking straight. The system is designed as a game where children are trained to avoid veering by exploiting the properties of a virtual sound environment. The game principles and system architecture are presented and referenced in the framework of the above cited curricula for blind children. In Section 3 authors describe the experimental set up and the results of a pilot study that involved 6 blind children aged from 5 to 8 years. The experiment has already been presented in a previous publication [24], but in the present paper new analysis methods have been applied. The new results are discussed and compared to similar research in Section 4, where perspectives for further work integrated with blind children needs are considered.

\section{Following the Cuckoo Sound}

Following the Cuckoo Sound is a responsive floor designed to train blind children to avoid veering using interactive audio. The term responsive floor indicates a rectangular surface of $3 \times 4 \mathrm{~m}$ placed under the range of a camera hanging from the ceiling of the room where it is possible to track the presence and movements of one 


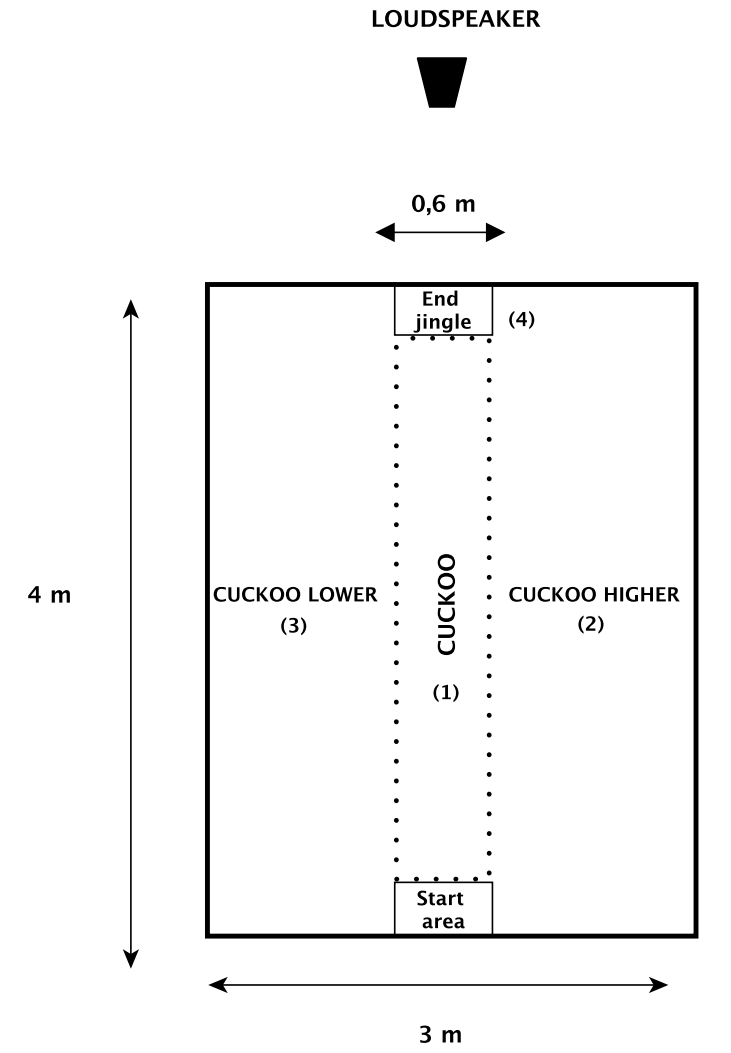

Figure 1. The area of the Following the Cuckoo Sound responsive floor with the 4 sound zones

or more users ${ }^{5}$. In this way the blind walker's position is linked to the audio output that can be changed interactively.

\subsection{Sound Design and Game Elements}

In her research about blind walkers' veering Susan Millar [25] found that veering can be influenced by a sound source, exactly as it happens in spatially directed locomotion of every-day life. Therefore, Following the Cuckoo Sound uses the intermittent sound of a cuckoo as a fixed beacon to drive children along a $4 \times 0.6 \mathrm{~m}$ corridor put in the middle of the responsive floor, as depicted in Figure 1. The interactive audio environment is formed by a natural soundscape which plays in the background and by 4 sound zones. As soon as the child occupies the Start area, the sounds of a wood are heard together with the cuckoo sound (sound zone 1). The loudspeaker source, put just in front of the corridor, permits a strong and clear guidance on the path. If the child walks inside the corridor the cuckoo sound continues unaltered. If

\footnotetext{
${ }^{5}$ Properly responsive floors are systems that employ pressure sensitive tiles to detect the position of a person on a floor, but the term is commonly extended also to systems based on computer vision, as in the present case.
}

the child gets off track on the right side the cuckoo sound becomes higher in frequency (sound zone 2), and if the child goes on the left side the sound becomes lower (sound zone 3). Thus, the differences in the sound of the cuckoo are used to mark if the child is going in the wrong direction and are intended as an invitation to correct it. Finally, as in a video games, when the child reaches the End position a final jingle notifies that the target has been successfully reached (sound zone 4$)^{6}$.

\subsection{System Architecture}

The technological equipment of Following the Cuckoo Sound is composed by a video camera, a long powered USB cable for camera connection, a computer, a green carpet, and a loudspeaker. The camera is positioned on the ceiling and looks down in the direction of the floor. It is connected by a long powered USB cable to the computer for data delivery. The carpet's color has been chosen has an optimal background to enhance the camera vision and to avoid excessive light reflection that could altere the visual data and that could be visible even to blind children. A single loudspeaker is positioned just in front of the corridor area where the cuckoo sound is heard. The system relies upon two software modules: the Zone Tracker application for camera data processing [26] and a Max/MSP [27] patch for the audio production. The RGB video data coming from the ceiling-mounted camera are processed by the Zone Tracker application. After background subtraction and morphological image processing, the algorithm obtains the blob of the user and outputs the Cartesian coordinates of its centroid. These data are transmitted via Open Sound Control (OSC) [28] to the Max/MSP patch where the mapping functions and audio files are stored. The system can also record the couple of Cartesian coordinates of the person's position with a frequency of 20 couples per second and store them for documentation or further processing.

\section{Assessment}

A pilot study to evaluate Following the Cuckoo Sound has been conducted at the Robert Hollman Foundation ${ }^{7}$ in Padova (Italy). The study aimed at verifying if, after having walked along the corridor and having followed the cuckoo sound, the children are able to reduce veering also in the absence of the audio guide.

\footnotetext{
${ }^{6} \mathrm{~A}$ video showing Following the Cuckoo Sound while being tested at the Robert Hollman Institute (Padova, Italy) can be found at https://youtu.be/yUkPcD1M-OQ.

${ }^{7}$ http://www. fondazioneroberthollman.it/
} 
Table 2. Experiment participants' information

\begin{tabular}{|c|c|c|l|c|}
\hline Participant & Age & Sex & Desease & Particular Conditions \\
\hline \hline A & 5 & F & Retinal dystrophy & $\begin{array}{l}\text { Already experienced } \\
\text { in the use of the long cane }\end{array}$ \\
\hline B & 6 & M & Retinopathy of preterm (ROP) & $\begin{array}{l}\text { Perceives the light } \\
\text { in a darkened environment }\end{array}$ \\
\hline C & 5 & F & $\begin{array}{l}\text { Retinal dystrophy of Leber's amaurosis } \\
\text { and exudative retinopathy (Coats' disease) }\end{array}$ & - \\
\hline D & 6 & F & Retinopathy of preterm (ROP) & - \\
\hline E & 8 & M & Bilateral congenital glaucoma & Not congenitally blind \\
\hline F & 8 & F & Retinopathy of preterm (ROP) & - \\
\hline
\end{tabular}

\subsection{Participants}

Six completely blind children of both sexes (2 males), aged between 5 and 8 years were chosen for the experiment. Information about the participants, ophthalmic diseases and particular conditions are reported in Table 2. In the column named "Particular Conditions" authors report information about the status or the experience of the participants that could influence their experimental results.

\subsection{Procedure}

Authors arranged the experimental setup in the middle of a quiet room approximately of $8 \times 10 \mathrm{~m}$. Children were introduced in the room one at a time accompanied by their educator. A test assistant and a researcher were admitted in the room. Only the test assistant spoke to the children, while all the other people were as silent as possible. Each test was preceded by a short explanatory introduction about the task to accomplish and by an exploratory phase consisting of a walk on the active area to make the child test the environment. The organization of each test comprehended three phases: pre-test, test and post-test. In the pre-test children were accompanied by the test assistant to the Start area with their face and shoulders oriented toward the end of the straight path. The educator was at the end of the corridor in the same position of the loudspeaker. At the call of the educator children tried to reach the End point of the corridor for three times without any form of assistance, that is without any sound produced by the system or voice guidance produced by any person present in the room. In the second phase the children had to undergo the same procedure but this time they heard the audio output produced by the system as described in Section 2. The post-test was performed exactly in the same way as the pre-test.

\subsection{Method}

The characteristic of the system described in Section 2.2 were employed to record the position data of each

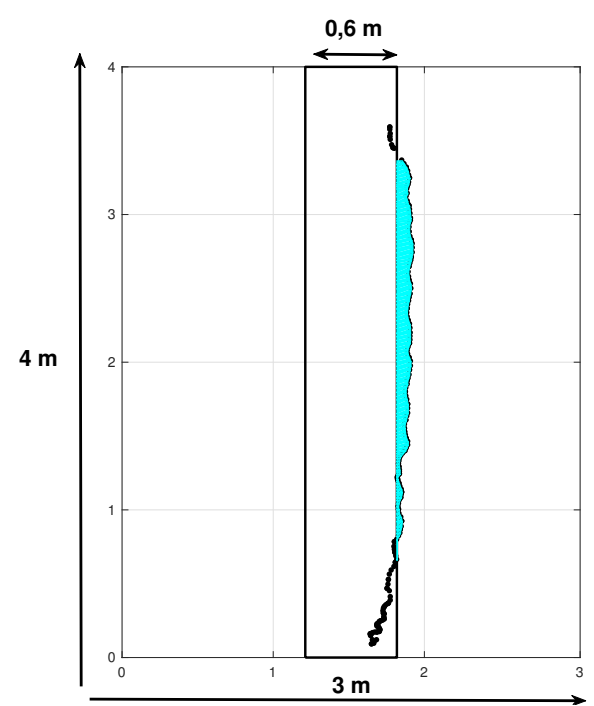

Figure 2. Participant $C$ pre-test. An example of veering area comprised between the corridor limit and the veering path

participant from when they occupy the Start area to when they reach the End point or exit the active area. Thus authors obtained a total of 9 records for each subject ( 3 for pre-test, 3 for the test and 3 for post-test). In a previous analysis [24], these data were used to calculate the veering area, that is the area comprised between the corridor limit and the veering path produced by the participant's walk, as represented in Figure 2. In the case that the veering path was inside the corridor area, no veering was recorded. In the present study authors rely on the same data but follow a different analytical approach. Following the findings of Kallie et al. (2007) [10] authors evaluated the veering as the result of two components: the initial orientation error and the systematic errors in step direction. In the examples of Figure 3 and 4 the veering path is the curved line marked with the little empty circles. The veering straight trajectory is the black dashed line starting from the veering path's origin to the last point of the path. The dashed line passing through the origin and perpendicular to the $X$ axis represents the optimal 


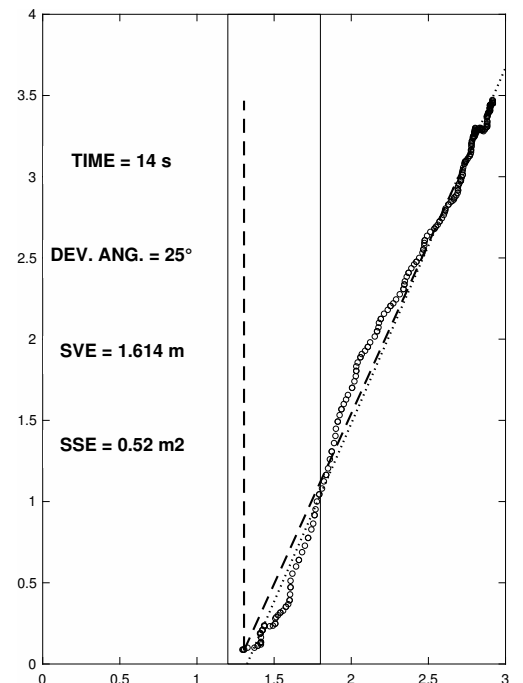

Figure 3. Participant B pre-test veering path with large deviation angle, small SSE and positive veering error

path trajectory. The deviation angle is calculated as the angle comprised between these two lines and is used to express the initial orientation error. To measure the effects of the errors in the step direction authors analyzed the best-fitting line by means of orthogonal linear regression. Differently from the ordinary linear regression, where the goal is to minimize the sum of the squared vertical distances between the $y$ data values and the corresponding $y$ values on the fitted line, in orthogonal regression the goal is to minimize the orthogonal (perpendicular) distances from the data points to the fitted line. The small-pointed line (well visible in Figure 4) is the interpolation line employed for the linear fitting. The SSE statistic (Sum of Squared Errors) represents a measure of how much the subject's veering path differs from the best-fitting line. The veering path of participant $B$ pre-test represented in Figure 3 has a large deviation angle $\left(25.49^{\circ}\right)$ but a veering path very near to the veering trajectory, expressed by and SSE value of .52. The path of Figure 4 has a much smaller deviation angle $\left(6.7^{\circ}\right)$ but a greater value of SSE (1.8), which corresponds to a wide curve, rather far from the veering straight trajectory. Other measures are the time employed to walk the path (i.e. the walking speed) and the signed veering error (SVE). This latter is expressed by the distance between the last point of the veering path and the corresponding point of the perpendicular line. If the error is positive the veering is towards the right, if it is negative the veering is towards the left.

\subsection{Results}

Authors discarded some of the $54 \mathrm{log}$ files recorded ( 9 for each participant) due to system failure or mistakes during the test. Particularly two pre-test files

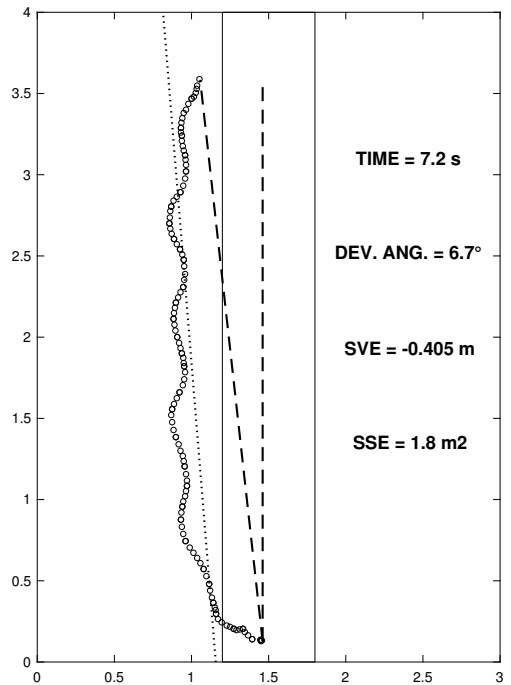

Figure 4. Participant $A$ post-test veering path with small deviation angle, large SSE and negative veering error

(from participant D and E) have incomplete data and consequently were considered not valid for analysis, while all the post-test files were admitted. Among some of the test files, authors were unable to analyze 6 trials (all the 3 files of participant C, one of participant B, $\mathrm{D}$ and $\mathrm{E})$ due an unforeseen behavior of the subjects during the test (see Section 4.2 for more details). Thus, the following analysis is based on 16 trials for pre-test, 12 trials for test and 18 trials for posttest. Participants' results are reported in Table 3. Pre, test and post-test values for constant error (degrees), variable error (degrees), sum of squared errors $\left(\mathrm{m}^{2}\right)$ and time (seconds) are calculated as the average of each participant's valid trials. As in the present study there is a small number of participants such that the normal distribution of data cannot be assumed, authors performed the Mann-Whitney $U$-test for pre- and posttest as well as for pre- and test means. The $U$-test reports a statistically significant difference only for SSE pre-test and test $(u(11)=-2.56, p<.05)$ and for times pre-test and test $(u(11)=-2.25, p<.05)$

Constant and Variable Error. Following the method proposed by Guth and LaDuke [8], authors evaluate the initial orientation error employing to different measurements: the constant error (CE) that is the mean of the deviation angles recorded in the various trials, and the variable error (VE) that indicates the degree of stability in the CE. In Guth and LaDuke's study the $\mathrm{VE}$ is expressed by the standard deviation of deviation angles. As in the present study there is a small number of trials such that the normal distribution of data cannot be assumed, authors calculated VE as the standard error of the deviation angles instead of the standard deviation employed by Guth and LaDuke. 
Table 3. Constant error (means of deviation angles), Variable error (standard error of deviation angles), Sum of Squared Errors (SSE) and Time results for pre-, test and post-test

\begin{tabular}{|c|c|c|c|c|c|c|c|c|c|c|c|c|}
\hline \multirow{2}{*}{ Participant } & \multicolumn{3}{|c|}{$\begin{array}{c}\text { Constant Error CE } \\
\text { (degrees) }\end{array}$} & \multicolumn{3}{|c|}{$\begin{array}{c}\text { Variable Error VE } \\
\text { (degrees) }\end{array}$} & \multicolumn{3}{|c|}{$\begin{array}{l}\text { Sum of Squared Errors SSE } \\
\left(\mathrm{m}^{2}\right)\end{array}$} & \multicolumn{3}{|c|}{$\begin{array}{c}\text { Time } \\
(\mathrm{s})\end{array}$} \\
\hline & pre & test & post & pre & test & post & pre $^{\star}$ & test $^{*}$ & post & pre $^{*}$ & test $^{*}$ & post \\
\hline $\mathrm{A}$ & 3.89 & 2.43 & 3.73 & 3.82 & 1.27 & 1.52 & 0.31 & 42.04 & 1.07 & 6.17 & 39.16 & 6.43 \\
\hline B & 13.67 & 1.27 & 5.85 & 7.06 & 0.32 & 2.74 & 0.88 & 57.95 & 1.49 & 13.38 & 41.10 & 7.80 \\
\hline C & 25.67 & - & 6.59 & 18.92 & - & 1.71 & 0.72 & - & 0.31 & 9.82 & - & 6.20 \\
\hline $\mathrm{D}$ & 7.55 & 4.41 & 25.38 & 7.26 & 3.30 & 8.08 & 0.87 & 2.13 & 0.66 & 7.93 & 13.65 & 13.95 \\
\hline $\mathrm{E}$ & 3.98 & 29.00 & 4.52 & 1.91 & 25.13 & 1.29 & 0.09 & 154.39 & 0.69 & 4.20 & 47.6 & 11.58 \\
\hline $\mathrm{F}$ & 11.34 & 2.53 & 11.30 & 1.58 & 0.17 & 2.98 & 4.39 & 192.69 & 0.44 & 11.73 & 37.73 & 6.27 \\
\hline Mean & 11.67 & 8.71 & 9.14 & 6.76 & 6.03 & 3.06 & 1.30 & 99.04 & 0.77 & 9.22 & 37.15 & 8.71 \\
\hline SE & 1.40 & 5.47 & 2.43 & 2.22 & 3.92 & 0.88 & 0.73 & 49.02 & 0.18 & 11.51 & 11.51 & 1.14 \\
\hline
\end{tabular}

* significant at $p<.05$

Signed Veering Error (SVE). The number of signed veering errors are reported in Table 4 . The analysis of signs of the veering errors reports the $29.4 \%$ of negative values (veering to the left) both in pre- and in post-test and the $50 \%$ of negative and positive values (veering to the right) in the test.

\section{Discussion}

In this section the above presented results will be discussed with respect to the veering correction, the relationship between speed and veering errors, the test data and the analysis of signed veering errors (SVE). A qualitative analysis about children's behavior during the experiments follows in Section 4.2.

\subsection{Quantitative Results}

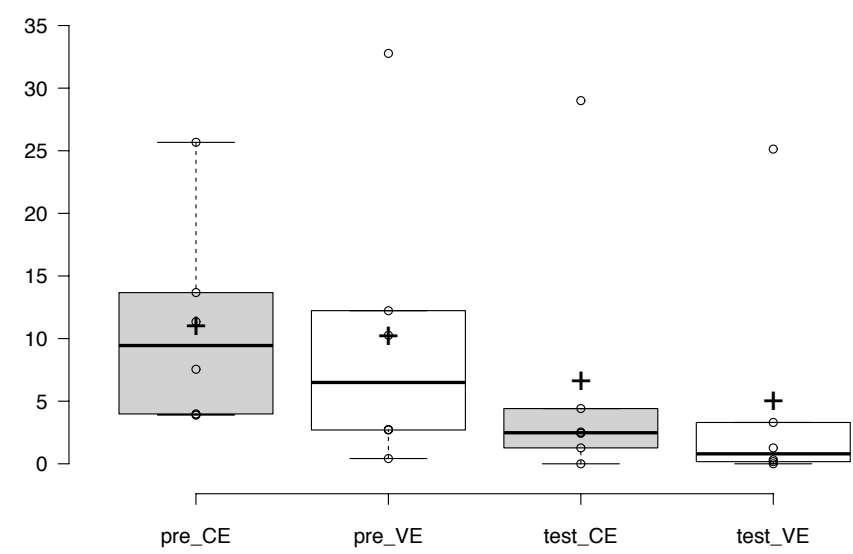

Figure 5. Boxplot of constant and variable error (CE and VE) in pre-test and test
Table 4. Veering errors directions in pre-test, test and post-test

\begin{tabular}{|c|c|c|c|c|c|c|}
\hline \multirow{3}{*}{ Participant } & \multicolumn{6}{|c|}{ Signed Veering Errors } \\
\hline & \multicolumn{2}{|c|}{ Pre } & \multicolumn{2}{|c|}{ Test } & \multicolumn{2}{|c|}{ Post } \\
\hline & $\mathrm{L}$ & $\mathrm{R}$ & $\mathrm{L}$ & $\mathrm{R}$ & $\mathrm{L}$ & $\mathrm{R}$ \\
\hline$\overline{\mathrm{A}}$ & 1 & $\overline{2}$ & $\overline{2}$ & 1 & 1 & $\overline{2}$ \\
\hline $\mathrm{B}^{* *}$ & 1 & 2 & 0 & 2 & 1 & 2 \\
\hline$C^{* *}$ & 1 & 2 & - & - & 0 & 3 \\
\hline $\mathrm{D}^{* * *}$ & 1 & 1 & 2 & 0 & 0 & 3 \\
\hline $\mathrm{E}^{*}$ & 0 & 2 & 1 & 1 & 3 & 0 \\
\hline $\mathrm{F}$ & 0 & 3 & 1 & 2 & 0 & 3 \\
\hline 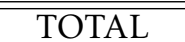 & 4 & $\overline{12}$ & $\overline{6} 6$ & 6 & 5 & $\overline{13}$ \\
\hline \multicolumn{7}{|c|}{${ }^{*}$ incomplete records in the pre-test } \\
\hline ** incomplete & cord & in $t$ & & & & \\
\hline
\end{tabular}

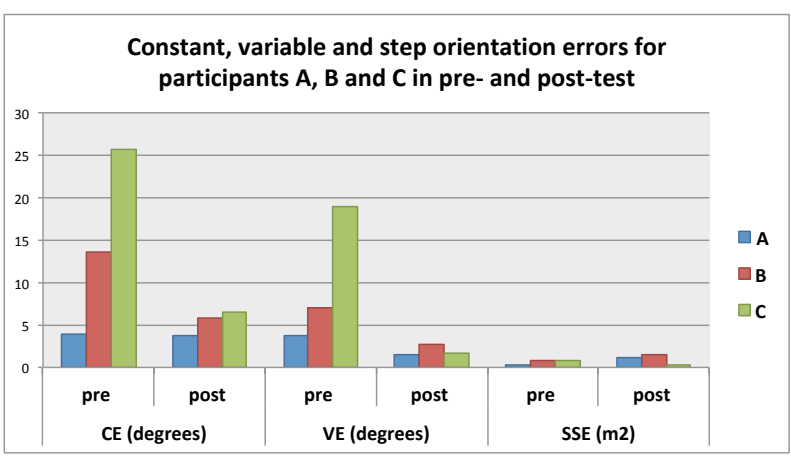

Figure 6. Comparative chart of veering correction results for participant $A, B$ and $C$

Veering correction analysis. The effects of the audio beacon chosen for this experiment in correcting participants' initial orientation errors (the cuckoo sound) can be evaluated from the analysis of the boxplots of Figure 5. Also if the mean differences are 
not statistically significant, the boxplots show how the constant (CE) and variable (VE) errors decrease in the test due to the orientation effect of the audio beacon. Constant error decreases in post-test for participants $A$, B C and F, but only participants A, B, C have a decrease also in variable errors. As far as concerns the errors in the step direction expressed by SSE values, participants $\mathrm{A}, \mathrm{B}$ and $\mathrm{E}$ increase SSE, while $\mathrm{C}, \mathrm{D}$ and $\mathrm{F}$ decrease. Thus, only participant $C$ improves in constant, variable and step direction errors (see Figure 6). Within the limits of this study it is also possible to evaluate the effects of the participants' particular conditions on their performance. Participant A was already trained in the use of the long cane and participant E was not congenitally blind. Both these participants report the lowest means of CE in pre- and post-test (3.81 for A and 4.38 for E) and also the lowest VE (2.67 for A and 1.60 for E), but only participant E has the lowest SSE mean in pre- and post-test (0.39). Of course it is impossible to generalize on participants' particular conditions due to the lack of repeated trials and data from other blind children with the same characteristics.

Speed and veering errors. Literature about veering report significant negative correlation between veering and walking speed [29], also if the interpretation of these findings has been critically discussed by Guth and LaDuke [8]. As global data in the present study show no significant correlation between angular deviation/SSE and speed, authors examined the paths walked in the shortest and in the longest times among both pre- and post-test recordings. Participant B's path represented in Figure 7 is nearly a line. Beyond the shortest time, it has the lowest deviation angle $\left(.04^{\circ}\right)$ and the lowest SSE value (.016). The path of Figure 8 , walked in the longest time of $25 \mathrm{~s}$, has a deviation angle of $9^{\circ}$, a value near to the constant error means in Table 3 and a SSE value of 12 , the largest in our sample. These findings seem to confirm that veering errors are connected to walking speed, also if the long times and large SSE of participant $\mathrm{F}$ pre-test records are probably due to esitation in the starting phase of the walk. Once again, these are observations biased by the limitations of the present study and which need further assessment to generalize.

Test Data. Table 3 reports all the data obtained in the present study. While differences in pre- and post-test are used to measure the effects of veering correction, the test data need some further interpretation. CE and VE test data have already been discussed in Section 4.1 as the effect of the audio beacon redirection. SSE and time show a statistically significant increase in the test with respect to pre-test. This is due to the behavior of participants who employed a very long time in exploring the environment instead of simply walking



Figure 7. Participant B's post-test veering path walked in the shortest time $(2.4 \mathrm{~s})$

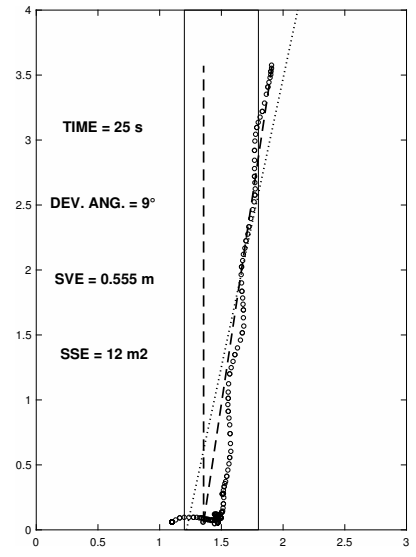

Figure 8. Participant F's pre-test veering path walked in the longest time (25 s)

straight along the shortest line to the final point. As a consequence, also SSE values increase.

Signed veering errors. Table 4 shows the distribution of veering directions in pre-test, test and post-test records. The great majority of records report a veering on the right side (approx. 75\%) but this seems to be the result of a random orientation of the body rather than of participants' repeated attitudes. Only in the test, veering is equally distributed in the right and in the left side, perhaps as a consequence of the directing effect of the audio beacon.

\subsection{Qualitative analysis}

In this section authors evaluate the children's behavior during the test and try to link the experience gained during the Following the Cuckoo Sound's experiments with the guidelines for blind children curriculum presented in Section 1.1 and 1.2.

Application Design and the Needs of Blind Children. Following the Cuckoo Sound fits some important points 
of the curriculum programs for blind children. The quantitative data analysis presented in Section 4.1 show the effects for orientation and mobility training of a short-term activity in the application's interactive environment. In spite of the efforts of the test assistant, it was extremely difficult to control the children's behavior during the test when the environment became active with all its sound playing (see Section 4.1 . Children were fascinated by interactive audio and were eager to explore all the active space, without caring too much to remain inside the central corridor. As can be seen from Figure 9, participant F explored the effect of walking outside the corridor more than once and in both directions. This is the reason why authors could admit only 12 test files for analysis.

Sensory efficiency. The ability to pay attention to environmental signals - such as sound in this case is a fundamental aspect of blind children curriculum as the senses are used as a substitution of vision. But this ability is not obvious at all and still requires effort and training. Blindness deprives children not only of vision but brings in many other problems such as the lack of confidence, insecurity, closure or shyness. For instance, one of the participants in the present study was so impressed by sound to ask the test conductor to turn down the volume of audio. Whatever the causes of such behavior, it is important to work for removing these obstacles which can prevent blind children to enjoy all the richness of the world of sounds. The training in interactive environments such as Following the Cuckoo Sound provide in the long term a sense of confidence which is the necessary pre-condition of sensory efficiency.

Recreation and leisure with interactive audio. In the design of the audio elements of Following the Cuckoo Sound authors employed natural as well as artificial sounds. The virtual soundscape used as sound background can provide a sense of reality and immersion. Interactive audio has the function to warm up children's attention and curiosity in a fun way, as the discovery of the effects of movement on audio is a powerful element of amusement. The start and final jingles act as signals in the same way as in video games. Thus, the exercise to train the sensorimotor ability in walking straight can be done for a longer time exploiting the potentials of these game elements.

A new approach to technology. The use of assistive technology is another of the points of blind children' curriculum as technology can be a great support for blind people. Unfortunately many devices require a specific training and often are rejected by users for their invasiveness and cognitive load, as pinpointed in Section 1.4. In Following the Cuckoo Sound authors employ a responsive floor as a computer interface. This kind of technology is not invasive but pervasive because

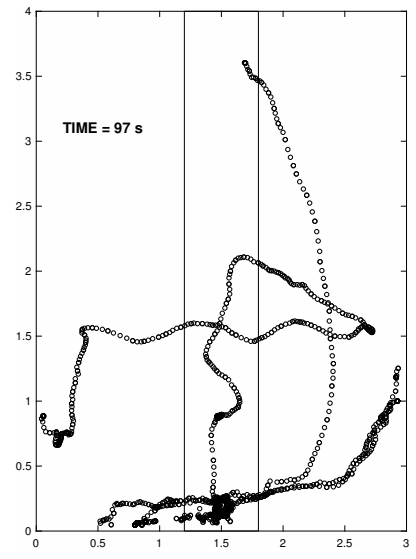

Figure 9. Example of child's behavior during the test

users are immersed in the active space and interact with it by moving their bodies, exactly as they do in common life. These human computer interaction elements may open the way to a new kind of assistive technology, which has the potentials of meeting blind children's needs in a more natural and effective way.

\section{Conclusion}

In this paper authors analyzed veering with respect of $\mathrm{CE}, \mathrm{VE}$ and the step direction errors (SSE). The analysis of the single participant's results show improvements of 2 participants out of 6 for CE and VE, and of only 1 participant for CE, VE and SSE. Other aspects of veering were analyzed, such as its relationship with walking speed and the influence of body posture in the veering towards the right or the left side. Anyway the main contribution of this paper are the data of children behavior during the test, which showed a great increase in the test times, due to interest and curiosity about the interactive environment. This suggests that not only the task of walking straight but also other attention redirection tasks may be employed to increase children confidence while moving in space. As a consequence Following the Cuckoo Sound can be evaluated in a much wider context than veering, that is in the general view of blind children curriculum needs such as sensory efficiency, recreation and leisure and, as a future target, social interaction.

Acknowledgement. The authors would like to thank Dr. Vittorina Schoch, Clinical Director and Dr. Maria Eleonora Reo Administrative Director of the Padua Center of the Robert Hollman Foundation for their cooperation in the organization of the experiments of the Following the Cuckoo Sound application.

\section{References}

[1] (2010-2012), Global data on visual impairments 2010. URL http://www.who.int/blindness/ 
GLOBALDATAF INAL f orweb . pdf.

[2] Gogate, P., Gilbert, C. and ZIN, A. (2011) Severe visual impairment and blindness in infants: causes and opportunities for control. Middle East African journal of ophthalmology 18(2): 109.

[3] (2018), The expanded core curriculum for blind and visually impaired children and youths - american foundation for the blind. URL https://tinyurl.com/ ybwqj jz6.

[4] (1999), Guide to curriculum for visually impaired children. URL https : / / tinyurl . com/ yb7ao4vc.

[5] (2018), All blind children of texas. URL http://www.abctx.org/blog/ origins-of-the-expanded-core-curriculum.

[6] Rouse, D.L. and Worchel, P. (1955) Veering tendency in the blind. New Outlook for the Blind.

[7] Cratty, B.J. and Williams, H.G. (1966) Perceptual Thresholds of Non-Visual Locomotion, Part II. (ERIC).

[8] Guth, D. and LaDuke, R. (1994) The veering tendency of blind pedestrians: An analysis of the problem and literature review. Journal of Visual Impairment $\mathcal{E}$ Blindness

[9] Souman, J.L., Frissen, I., Sreenivasa, M.N. and Ernst, M.O. (2009) Walking straight into circles. Current Biology 19(18): 1538-1542.

[10] Kallie, C.S., Schrater, P.R. and Legge, G.E. (2007) Variability in stepping direction explains the veering behavior of blind walkers. Journal of Experimental Psychology: Human Perception and Performance 33(1): 183.

[11] Loomis, J.M., Klatzky, R.L., Golledge, R.G. and Philbeck, J.W. (1999) Human navigation by path integration. Wayfinding behavior: Cognitive mapping and other spatial processes : 125-151.

[12] Boyadjian, A., Marin, L. and Danion, F. (1999) Veering in human locomotion: the role of the effectors. Neuroscience letters 265(1): 21-24.

[13] Long, R.G. and Hill, E. (1997) Establishing and maintaining orientation for mobility. Foundations of orientation and mobility $\mathbf{1}$

[14] Guth, D. (2007) Why does training reduce blind pedestrians veering (John J. Rieser).

[15] Cuturi, L.F., Aggius-Vella, E., Campus, C., Parmiggiani, A. and Gori, M. (2016) From science to technology: Orientation and mobility in blind children and adults. Neuroscience E Biobehavioral Reviews 71: 240-251.

[16] Sohl-Dickstein, J., Teng, S., Gaub, B.M., Rodgers, C.C., Li, C., DeWeese, M.R. and Harper, N.S. (2015) A device for human ultrasonic echolocation. IEEE Transactions on Biomedical Engineering 62(6): 1526-1534.

[17] Velãzquez, R., BazÁn, O. and Magaña, M. (2009) A shoe-integrated tactile display for directional navigation. In Intelligent Robots and Systems, 2009. IROS 2009.
IEEE/RSJ International Conference on (IEEE): 1235-1240.

[18] Gori, M., Cappagli, G., Tonelli, A., Baud-Bovy, G. and Finocchietti, S. (2016) Devices for visually impaired people: High technological devices with low user acceptance and no adaptability for children. Neuroscience \& Biobehavioral Reviews 69: 79-88.

[19] Janssen, J., Verschuren, O., Renger, W.J., Ermers, J., KetelaAR, M. and van Ee, R. (2017) Gamification in physical therapy: More than using games. Pediatric Physical Therapy 29(1): 95-99.

[20] Merabet, L. and Sánchez, J. (2009) Audio-based navigation using virtual environments: combining technology and neuroscience. AER Journal: Research and Practice in Visual Impairment and Blindness 2(3): 128137.

[21] (2012) Dynamic spatial positioning system based on sounds and augmented reality for visually impaired people.

[22] Sánchez, J., Espinoza, M. and Garrido, J. (2012) Videogaming for wayfinding skills in children who are blind. In Proc. 9th Intl Conf. on Disability, Virtual Reality and Assoc. Technologies, PM Sharkey, E Klinger (Eds): 131140 .

[23] Magnusson, C., Rydeman, B., Finocchietti, S., Cappagli, G., Porquis, L.B., Baud-Bovy, G. and Gori, M. (2015) Colocated games created by children with visual impairments. In Proceedings of the 17th International Conference on Human-Computer Interaction with Mobile Devices and Services Adjunct, MobileHCI '15 (New York, NY, USA: ACM): 1157-1162. doi:10.1145/2786567.2794350, URL http : / / doi .acm.org/10.1145/2786567.2794350.

[24] Mandanici, M., Rodà, A., Canazza, S. and Cavagnoli, G. (2017) Following the cuckoo sound: A responsive floor to train blind children to avoid veering. In International Conference on Smart Objects and Technologies for Social Good (Springer): 11-20.

[25] Millar, S. (1999) Veering revisited: Noise and posture cues in walking without sight. Perception 28: 765-780.

[26] Amico, L. (2012) La Stanza Logo-Motoria. Un Ambiente multimodale interattivo per l'insegnamento a bambini in situazione di multi-disabilità. Master's thesis, Dipartimento di Ingegneria dell'Informazione, Università di Padova.

[27] Max/msp https://cycling74.com/.

[28] WRIGHT, M. (1997) Open sound control-a new protocol for communicationg with sound synthesizers. In Proceedings of the 1997 International Computer Music Conference: 101-104.

[29] Klatzky, R.L., Loomis, J.M., Golledge, R.G., Cicinelli, J.G., Doherty, S. and Pellegrino, J.W. (1990) Acquisition of route and survey knowledge in the absence of vision. Journal of motor behavior 22(1): 19-43. 